\title{
The cerebellum, the hypothalamus and behavior
}

\author{
Ivana Gritti
}

Department Clinical Science-Luigi Sacco, School of Medicine and Surgery, University of Milan, Milano, Italy; Ivana.Grittti@unimi.it

Received 29 April 2013; revised 1 June 2013; accepted 8 June 2013

Copyright (C) 2013 Ivana Gritti. This is an open access article distributed under the Creative Commons Attribution License, which permits unrestricted use, distribution, and reproduction in any medium, provided the original work is properly cited.

\begin{abstract}
The cerebellum has been classically considered as the subcortical center for motor control. However, accumulating experimental evidence has revealed that it also plays an important role in cognition, for instance, in learning and memory, as well as in emotional behavior and nonsomatic activities, such as visceral and immunological responses.
\end{abstract}

Keywords: Cerebellum; Hypothalamus; Behavior; Memory; Plasticity; Learning; Repair

\section{INTRODUCTION}

At the back of our skull, perched upon the brain stem under the overarching mantle of the great hemispheres of the cerebrum, rests a baseball-sized, bean-shaped lump of gray and white brain tissue. This is the cerebellum. The cerebellum discloses an intense, highly distinctive activity to the sensitive instruments and manipulations of modern brain physiology. Its signals have begun to tell us that, though seemingly having no direct control over body functions, it monitors and coordinates the brain's other centers, mediating between them and the body. For Medieval anatomists, the cerebellar cortex was the arbor vitae, the purported seat of the soul.

Through its connections with the brain's motor centers the cerebellum receives impulses similar to those sent out to the muscles, as well as from the end organs of the peripheral nervous system, the so-called proprioceptive endings, in the contracting muscles. The cerebellum compares these two sets of impulses and transmits modified impulses back to the motor centers in the brain and, indirectly, out to the muscles. This checking of response against command and fine-tuning of command to response smoothes and coordinates muscle action. When the action involves two opposing sets of muscles, the cerebellum integrates the data for both, coordinating contraction of the flexor muscles at the front of the arm with relaxation of the extensor muscle at the back. This function of the cerebellum was recognized as early as 1898 by the great British physiologist Charles Sherrington, who called it the head ganglion of the proprioceptive system.

Further investigation demonstrates that the cerebellum plays a similar role in maintaining the body's equilibrium; in this instance, the initial impulses arise in the semicircular canals of the inner ear. The cerebellum integrates these signals with the proprioceptive data coming from the opposing group of muscles that maintain body posture. As the product of this integration, the impulses are sent out to both the lower and higher nervous centers directing the intricate performance of the many muscles in action even when the body is merely standing still. The cerebellum was thus established as a center governing the musculature by coordinating directed action both consciously and unconsciously.

As in the cerebrum, the various functions of the cerebellum are localized in distinctly defined areas of its cortex. These areas have been mapped by detecting and plotting cortical electrical activity. Control of the body's equilibrium, for example, is localized in the extreme front and rear surfaces of the cerebellum. The proprioceptive areas appear as actual maps of the body on the cortex: two distorted "homuncoli", one face-on and the other in double profile back-to back. It was long thought that plotting of these areas had completed the map of the cerebellar cortex, in keeping with the notion that the cerebellum's activity was restricted to maintaining the body's equilibrium and posture and coordinating muscle movements. It was only later found that the cerebellum was equally involved in coordinating the sensations of touch, hearing and vision. The prevailing theory at present is that the cerebellar circuitry is a control system imposed upon the basic ascending (sensory) and descending (motor) circuits of the nervous system [1-3]. 


\section{OSCILLATORY ACTIVITY OF THE CEREBELLUM}

The system works by generating electrical waves at the highest frequency in the nervous system, imposing its peculiar high frequency, low-amplitude characteristics upon all impulses that pass through it, often smothering the frequency amplitude characteristics of impulses originnating elsewhere in the nervous system (for a review see [4]).

\section{THE CEREBELLAR-HYPOTHALAMIC CIRCUITS}

There is sizable evidence documenting that integration is one of the major functions of the cerebellum and that it is involved in still more diverse aspects of the nervous system. For example, cerebellar influences on visceral functions have been described (for a review see [5]). The cerebellum, via its connection with the hypothalamus, is involved in controlling vasomotor reflexes and blood pressure wave, carotid sinus reflexes, and the somatic and autonomic manifestations of shame rage, pupil nictitating membrane, respiration, gastrointestinal functions (for a review see [5]). The reciprocal cerebellar hypothalamic pathway has been suggested to provide circuits through which autonomic hypothalamic processes may be influenced by the cerebellum [5-7]. The cerebellar connections into the rostral basal forebrain substantiate its role in emotional expression and behavior [8] (for a review see [5]).

The central circadian clock of the mammalian brain resides in the suprachiasmatic nucleus of the hypothalamus. At the molecular level, the circadian clockwork of the suprachiasmatic nucleus constitutes a self-sustained autoregulatory feedback mechanism reflected by the rhythmic expression of clock genes. A recent discovery is the circadian oscillations of molecular clock components in the cerebellar cortex, some of which are regulated by the suprachiasmatic molecular clock [9].

Somatic-nonsomatic integration is critical for the generation and execution of appropriate and coordinated behavioral response to changes in internal and external environments. Intriguingly, the central histaminergic and orexinergic systems originating from the hypothalamus, a high autonomic regulatory center, innervate almost the entire brain including the cerebellum. Furthermore, it has been suggested that the hypothalamic histaminergic and orexinergic systems bridging the nonsomatic center to somatic motor structures may actively modulate cerebellar neurons and subsequently participate in motor control and somatic-nonsomatic integration [10]. Cerebellar fastigial glutamatergic neurons participate in modulating humoral immunity, and this effect is mediated by the hypothalamus via fastigial-hypothalamic glutamatergic transmission [11].

\section{CEREBELLUM AND NON-MOTOR FUNCTIONS AND NEUROPSYCHIATRIC DISORDERS}

Cerebellar dysfunction is not only manifested as ataxia, a common symptom of various neurological disorders. There is now considerable evidence for a link between the cerebellum and non-motor functions and neuropsychiatric disorders, including dyslexia, autism, and attention deficit hyperactivity disorder. In addition, cerebellar pathologies have been correlated with various emotional disorders such as depression [12]. The cerebellum is known to play a role in motor learning, like adaptation of the vestibulo-ocular reflex and eye-blink conditioning, through long-term depression of synapses between parallel fibers and Purkinje cells. The cerebellar vermis is involved in the retention of fear memory consolidation $[13,14]$ (for a review see [5]). Owing to its myriad functions of integration and coordination, the cerebellum provides a suitable model to study neuronal plasticity, learning, and repair [2,15-20].

\section{ACKNOWLEDGEMENTS}

Thanks are given to K. Britsch for reading the manuscript.

\section{REFERENCES}

[1] Brodal, A. (1981) Neurological anatomy. Oxford University Press, Oxford.

[2] Strata, P. (2009) David Marr's theory of cerebellar learning: 40 years later. Journal Physiology, 587, 5519-5520. doi:10.1113/jphysiol.2009.180307

[3] Strata, P., Provini, L. and Redman, S. (2012) On the concept of spinocerebellum. Proceeding National Academy Science of USA, 109, E623.

doi:10.1073/pnas.1121224109

[4] Dalal, S.S., Osipova, D., Bertrand, O. and Jerbi, K. (2013) Oscillatory activity of the human cerebellum: The intracranial electrocerebellogram revisited. Neuroscience Biobehavioral Reviews.

[5] Zhu, L., Sacco, T., Strata, P. and Sacchetti, B. (2011) Basolateral amygdala inactivation impairs learning-induced long-term potentiation in the cerebellar cortex. PLoS ONE, 6, e16673. doi:10.1371/journal.pone.0016673

[6] Dietrichs, E. (1984) Cerebellar autonomic function: Direct hypothalamocerebellar pathway. Science, 223, 591593. doi:10.1126/science.6198719

[7] Zhu, J.N., Yung, W.H., Chow, B.K.C., Chan, Y.S. and Wang, J.J. (2006) The cerebellar-hypothalamic circuits: Potential pathways underlying cerebellar involvement in somatic-visceral integration. Brain Research Review, 52, 93-106. doi:10.1016/j.brainresrev.2006.01.003

[8] Harper, J.W. and Heath, R.G. (1973) Anatomical connec- 
tions of the fastigial nucleus to the rostral forebrain in the cat. Experimental Neurology, 39, 285-292. doi:10.1016/0014-4886(73)90231-8

[9] Rath, M.F., Rode, K. and Moller, M. (2012) Circadian oscillations of molecular clock components in the cerebellar cortex of the rat. Chronobiology International, 29, 1289-1299. doi:10.3109/07420528.2012.728660

[10] Zangh, X.Y., Yu, L., Zhuang, Q.X., Zhang, J., Zhu, J.N. and Wang, J.J. (2013) Hypothalamic histaminergic and orexinergic modulation on cerebellar and vestibular motor control. Cerebellum, 12, 294-296. doi:10.1007/s12311-012-0442-y

[11] Cao, B.B., Han, X.H., Huang, Y., Qiu, Y.H. and Peng Y.P. (2012) The hypothalamus mediates the effect of cerebellar fastigial nuclear glutamatergic neurons on humoral immunity. Neurological Endocrinological Letters, 33, 393400.

[12] D’Angelo, E. and Casali, S. (2013) Seeking a unified frame work for cerebellar function and dysfunction: From circuit operations to cognition. Frontiers in Neuronal Circuits, 6, 1-20. doi:10.3389/fncir.2012.00116

[13] Sacchetti, B., Baldi, E., Ambrogi, L.C. and Bucherelli, C. (2002) Cerebellar role in fear conditioning consolidation. Proceeding of National Academy Science USA, 99, 84068411. doi:10.1073/pnas.112660399

[14] Sacchetti, B., Scelfo, B., Tempia, F. and Strata, P. (2004) Long-term synaptic changes induced in the cerebellar cortex by fear conditioning. Neuron, 42, 973-982. doi:10.1016/j.neuron.2004.05.012

[15] Strata, P. and Rossi, F. (1998) Plasticity of the olivocerebellar pathway. Trends Neuroscience, 21, 407-413.

[16] Bravin, M., Morando, L., Vercelli, A., Rossi, F. and Strata, P. (1999) Control of spine formation by electrical activity in the adult cerebellum. Proceeding of National Academy Science USA, 96, 1704-1709. doi:10.1073/pnas.96.4.1704

[17] Morando, L., Cesa, R., Rasetti, R., Harvey, H. and Strata, P. (2001) Role of glutamate delta2 receptors in activitydependent competition between heterologous afferent fibers. Proceeding of National Academy Science USA, 98, 9954-5999. doi:10.1073/pnas.171098398

[18] Cesa, R., Morando, L. and Strata, P. (2003) Glutamate receptor d2 subunit in activity dependent heterologous synaptic competition. The Journal of Neuroscience, 23, 2363-2370.

[19] Scelfo, B. and Strata, P. (2005) Correlation between multiple climbing fiber regression and parallel fiber response development in the post-natal mouse cerebellum. European Journal of Neuroscience, 21, 971-978. doi:10.1111/j.1460-9568.2005.03933.x

[20] Grasselli, G. and Strata, P. (2013) Structural plasticity of climbing fibers and the growth-associated protein GAP43. Frontiers in Neuronal Circuits, 7, 1-7. doi:10.3389/fncir.2013.00025 